\title{
Critical Factors for the Success of Web-Based Learning
}

\author{
Ioannis Kazanidis, International Hellenic University, Greece \\ Stavros Ioannis Valsamidis, TEI of East Macedonia and Thrace, Greece \\ (iD https://orcid.org/0000-0001-7398-9073 \\ Sotirios Kontogiannis, University of Ioannina, Greece \\ (iD) https://orcid.org/0000-0002-1360-3367 \\ Soultana Ellinidou, Université Libre de Bruxelles, Belgium \\ https://orcid.org/0000-0001-6843-9253
}

\begin{abstract}
Success is the main purpose in any entity. So, in any educational institute, the education offered must be successful. It seems that some factors are critical to achieve it. Web-based learning (WBL) has some specific factors that are studied in this paper. These factors are the characteristics of instructors, students, information and communication technology (ICT), and ICT used by school support. In this perspective, the research purpose of this study is to present, investigate, and assess the factors that influence and lead to successfully use the web-based learning. It also studies the dependence of the proposed five factors and their interrelationships. The results based on a structured questionnaire that was distributed and completed in a Greek university. Both exploratory and confirmatory factor analyses were used.
\end{abstract}

\section{KEYWORDS}

Confirmatory Factor Analysis, Critical Factors, Exploratory Factor Analysis, Web-Based Learning

\section{INTRODUCTION}

The fact that some organizations seemed to be more successful than others caused the investigation for this observation. Some factors appeared to be critical for this success and characterized as critical. A factor that is critical to the success of the project is intuitively referred to as a Critical Success Factor (CSF). CSFs are variables that are fundamental to the success of the implementation, and an organization must handle these CSFs well in order to have a successful implementation (Frimpon, 2011).

The methodology, as a concept, is very simple: to any organization, some factors are critical for success in the sense that, if the objectives related to the factors are not achieved, the failure of the organization is certain, and in many cases disastrous. 
The concept of "success factors" was developed by Daniel (1961) with potential utility as an evaluation measure in libraries and information units. The methodology was refined and became popular by Rockart (1979) and even more, since 1981. Over the years, many scholars have applied the methodology in different areas, inside and outside the educational system. The method of CSFs has been applied in various fields such as technology, business sector and education. However in Web Based Learning (WBL) literature, there are not many studies for CSFs.

Previous studies have shown that various factors such as the characteristics of teachers and students, technology, university support, course content and knowledge management, and interactive applications can greatly influence the acceptance of online education by students (Ndubisi, 2004; Poon et al., 2004); Latifah \& Ramli, 2005; Selim, 2005; Rosenberg, 2001). If the online education system is successful, it will be more likely to be accepted by students.

There are some features of online education that need to be explored. These are the Critical Success Factors (CSFs) that make an online education system successful, of the desired quality, and generally do the job for which it was created. A wide variety of factors, which can influence the success of online learning environments, are known from the literature.

The aim of this study is to clarify the critical success factors of online education, as perceived by students, and then to investigate the relationships between these factors, proposing a new causal model. Four variables were defined as critical factors: Instructors' characteristics (Instructor), Students' characteristics (Student), Information and Communications Technology (Technology) and the Support by the school (Support). Finally, a fifth variable (Intention to Use) is used to measure the intention of students to use Web Based Learning.

The rest of the paper is organized as follows. Section 2 describes the literature review. Section 3 describes the background theory. Section 4 describes the methodology used. The results of a case study are reported in section 5. Section 6 presents a discussion about the approach and the results. We also draw some conclusions together with directions in the future in Section 7.

\section{LITERATURE REVIEW}

Researchers have identified different CSFs in e-learning. We cite them in chronological order as historical review.

McAlister, Rivera, \& Hallam (1999) presented about how important is the design during the implementation process of these types of programs. Twelve questions about e-learning education are given to an educational institution, in order to reassure the quality and the success of the e-learning education. The results indicated that the teachers should be familiar with the latest technological advances that they are going to use in their courses. Moreover, frequent interactive communication with their student should be their primary factor in order to pursue a successful e-learning education by replacing the "face to face" communication during the traditional classroom teaching.

Papp (2000) pointed out in his study about the critical education factors of a successful e-learning education following: literary property, suitability of the course in an online teaching environment, structure of the online course, frequently updating of the online course, design of a platform which support e-learning education and the ability to check the successful function of an online course.

Volery and Lord (2000) identified technology, instructor and previous use of technology from a student's perspective as the CSFs in e-learning. More specifically they define technology as the factor, which is related to the navigation and ease of access as well as the interface of the e-learning system. Moreover, the authors measure attitudes towards students and classroom interaction. Frimpon (2001) identified and measured seventeen CSFs through an exhaustive search; they were partitioned into 4 natural roles of Student, Instructor, Technology and Institution.

Sigala (2001) put a lot of effort into finding the critical factors that affect the efficiency of development, design and implementation of e-learning education. In her article, she analysed the theoretical background of the e-learning education and she also referred to possible factors that can 
affect the effectiveness of this method. She summarised that there are three categories: technology characteristics, student characteristics and teacher characteristics.

Alexander (2001) presented a general aspect of the design, the development and the implementation of the e-learning systems in universities. This aspect assumes that the e-learning education is successful through the combination of the students experience in e-learning, the teaching strategy of professors and the programming of the e-learning framework of training/ education. As far as the online courses, the professors should focus on the teaching strategies when other issues, such as the professors perception for education, have a big influence in the programming of courses, the development of teaching strategies and the learning level of students.

Soong, Chan, Chua, \& Loh (2001) identified as main CSFs of e-learning education: the human factors (the hypo-kinetic skills, the time that they are investing and the effort), the technical ability of professors and students, and the high level of cooperation between them, the adequate and the user-friendly infrastructure.

Honey (2001) tried to determine which factors can interfere with the success of the e-learning education. The first factor refers to the effective use of the technology by the teachers to students. Furthermore, students should have basic knowledge of computer use and this teaching process should be encouraged and actively supported by them. Honey makes clear that the e-learning education has a lot potentials and in conjunction with the fact that it is one of the most important learning opportunities in the education field, it can be developed even more in the upcoming years.

Govindasamy (2002) tried through his paper to present a teaching model as a prerequisite for the e-learning education, by highlighting seven key factors: institutional support, development of courses, teaching and learning, course structure, support of students, assessment and evaluation, and school support.

Other studies have shown that various factors such as Teachers' and Students' characteristics (Ndubisi, 2004; Poon, Low, \& Yong, 2004), the Technology (Poon, Low, \& Yong, 2004), the University support (Latifah \& Ramli, 2005), the courses context and the management of knowledge (Selim, 2005; Rosenberg \& Foshay, 2002) and the interactive applications (MacDonald, 2001) have great affection to the students, in order to accept the e-learning education. If the e-learning education system is working successfully, the students will easily accept and adapt it.

Friesen (2005) in his thesis examined eight CSFs. He proposed the following categories and he also analysed and categorised each one of that factors: (a) Institutional factors (infrastructure, sufficient resources for e-learning, etc.), (b) Factors that considered teachers (interaction with students, qualifications, etc.), (c) Factors that considered students (rate of learning, motivation, etc.), (d) Educational planning coverage factors (teamwork, wealthy learning resources, etc.), (e) Pedagogical factors (to provide an environment for students, relevancy and accuracy of content, etc.).

Selim (2005) highlighted the CSFs of e-learning education in the environment of a University. Specifically, these factors can be divided into four categories: professor, student, information technology and university support. The educational application of Information Technology (IT) can reveal the effectiveness of e-learning education. According to Selim, the CSFs include also the control and the attitude towards technology, the adequacy of computers, the interaction and collaboration, the content and design of e-learning courses, the ease of access, the infrastructure and the support. Selim (2007) also identified the CSFs of distance learning via the Internet as it is perceived by university students. A review that included 538 university students revealed eight categories of CSFs, each of which included a number of critical metrics acceptance and success. These critical success factors included: the characteristics of the instructor (related to technology, training method), student characteristics (motivation to participate in a distance learning program, sufficient computer knowledge, interactive collaboration and attitudes towards active learning activities), and technology (accessibility and infrastructure), and technical support.

White (2007) identifies as educational success factors on e-learning education: strategy, policy, procedures and tactics of university. Ngai, Poon, \& Chan (2007) expanded the technology acceptance 
model in order to include the technical support as a precursor and then the role of the extended model, considered the acceptance of WebCT from the user side. The data showed that technical support has a significant impact on the ease of use and usefulness, which are the main factors determining the attitude of LMS users.

McPherson and Nunest (2008), published an article on critical issues of e-learning about the fact that often not applied in practice, while they are obvious. After interviews, analysis and research, they identified four critical issues (critical factors) that help in the teaching of e-learning and are presented below: (a) personal issues between professors, (b) the course teaching model, (c) training of students and teachers, and (d) leadership issues.

Chao and Chen (2009), in their article about the construction of a fuzzy logic system for the evaluation of the criteria and the effectiveness of online education following an extensive study of the literature, they led to the selection of five CSFs: (a) equipment of e-learning education, (b) quality of the platform used by the University, (c) modern education, (d) graduation of students and (e) autonomous learning.

Sela and Sivan (2009) proposed nine success factors for enterprise-wide e-learning. These factors are divided into two categories: "must-have" factors and "nice-to-have" factors. The musthave factors include useful and easy to use e-learning tools, marketing, management support, the right organizational culture, and the existence of a real need for the organization. The "nice to have" factors include time to learn, support, mandatory learning, and incentives.

A study for the Critical Success Factors on Online Distance Learning in Higher Education identified 5 factors: (1) institutional management, (2) learning environment, (3) instructional design, (4) services support and (5) course evaluation. Each of these 5 factors includes several important elements that can assist to enhance the efficiency of online learning courses in higher education institutions (Cheawjindakarn, Suwannatthachote, \& Theeraroungchaisri, 2013).

A conceptual framework on the critical success factors of e-learning implementation in higher education was presented by (Basak, Wotto, \& Bélanger, 2016). The critical success factors that affect the successful implementation of e-learning are Technological Factors, Institutional Factors, Pedagogical Factors, Management Factors, Ethical Factors, Evaluation Factors, Resources Factors and the Social Interaction Factors.

A comparative study between academic staff and students revealed that the perspectives of students and academic staff differ, with there being nine factors for academic staff and seven for students. Categories that are common to both groups are: student characteristics, instructor characteristics, ease of access, and support and training (Alhabeeb \& Rowley, 2018).

The hierarchy Critical Success Factors affecting the higher technical education institutions by using Total Interpretive Structural Modeling (TISM) was presented by Kashiramka et al. (2019). They established the inter-linkages among ten critical success factors for enhancing the performance of these institutions. The findings revealed that autonomy and accountability coupled with the availability of sustainable funds are the driving factors for their success. Infrastructural facilities and establishment of centers of excellence act as amplification factors.

\section{BACKGROUND THEORY}

\subsection{Instructors Characteristics (Variable A1)}

Collis (1995) proved that a professor is a key to the success of e-learning education, claimed that "It is not the technology but the educational application of technology that defines the results of learning". However, in a flexible e-learning environment, the students may feel isolated because there is not any interaction between them and the professor. During the online courses, students frequently face technical problems. Consequently, the professor should have a good command of new technologies, in order to be able to face every problem that comes up. Also, the control and knowledge of technology 
should be combined with the professor's organisation skills. Haynes, Pouraghabagher, \& Seu (1997) pointed out that a well organised course by a professor is effective on coordination of a series of online courses. Furthermore, Fredericksen, Pickett, Shea, Pelz, \& Swan (2000) considered that the professors have already had a successful role in e-learning education. The professors should provide a high level of interaction and conversation between them and their students for a successful e-learning education. Also, they could influence and motivate their students, in order to easily accept the online environment (Ndubisi, 2004; Selim, 2005).

In our research, the factor "Instructors characteristics" includes 13 determined variables (A1.1-A1.13) for thorough research. The determined variables A1.1-A1.7 adopted by Selim (2005) and they previously used by Volery and Lord (2000). The determined variables A1.8 and A1.9 adopted by Lim, Hong, \&Tan (2008), in order to check the availability of professors. The determined variables A1.10-A1.13 are used to test the relationship between professor and e-learning education environment.

\subsection{Student Characteristics (Variable A2)}

Poon (2004), Folorunso, Ogunseye, \& Sharma (2006), Selim (2005) and Volery and Lord (2000) referred to some students' characteristics, like to be satisfied with the flexibility and the position of the system, the involvement and participation, the level of self-confidence, self-effectiveness in technology, the initiative, the motive and the concern about the influence of acceptance of e-learning education.

In order to determine the factor "Students characteristics", we defined 20 variables. The identifying variables A2.1 and A2.2 check the motivation of the student to use the e-learning education. The identified variables A2.3-A2.7 test the technical ability of students. The identified variables A2.8-A2.14 developed for testing the effectiveness of the content of e-learning courses, the structure and the design from the student's view. Finally, the determined variables A2.15-A2.20 developed, in order to test the attitudes and behaviours of students toward e-learning education. The first 14 determined variables adopted by Selim (2005) and the rest of the variables by Lim, Hong, \&Tan (2008). The identifying variables A2.1-A.2.7 have also used by Soong (2001).

\subsection{Information Technology (Variable A3)}

The technology infrastructure and technical support of the education system through the Internet also affect the acceptance of e-learning education by students. In order to pursue a successful e-learning education, the technology and the education system should be renewed and constantly maintained (Folorunso, Ogunseye, \& Sharma, 2006; Poon, Low, \& Yong, 2004; Selim, 2005).

McIntyre and Wolff (1998) mentioned that "One of the interaction forces in a web environment is the ability to capture, providing quick and imperative interaction and feedback to the students". It is worth mentioning that some studies used the technology acceptance model in initial or extended version (Ong, Lai, \&Wang, 2004; Drennan, Kennedy, \& Pisarki, 2005; Saadé \& Bahli, 2005; Ngai, 2007), while other studies depended on statements of teams that are focus on the added value and the level of computer use in education (Mitra, Lenzmeier, Steffensmeier, Avon, Qu, N., Hazen, 2000; Shuell \& Farber, 2001) and other studies used literature model that are related to the online meetings (Bures, Amundsen, \& Abrahmi, 2002) and the use of hypermedia (Tolhurst \& Debus, 2002).

The factor "Information Technology" includes 13 determined variables (A3.1-A3.13). These will are in order to test the reliability, the wealth, consistency and effectiveness of technology of Technological Educational Institution (TEI). The identifying variables A3.1 - A3.8 have previously used by Volery and Lord (2000) and test the ease of access and browse of the Internet on campuses, the Internet speed, the ease of use of websites, the effectiveness of user interface, the reliability of communication between students and professors. The determined variables A3.9-A3.13 developed to capture the effectiveness of infrastructure and information technology services that are available on TEI and they are used in order to test the reliability of network of TEI and the effectiveness of information systems for students. 


\subsection{Support from the Educational Institution (Variable A4)}

Latifah and Ramli (2005) mentioned that it should not be ignored the support of educational institution, in order to improve the e-learning education. They should provide better technological facilities, better copyrights, better authentication system and better human and technical material support (Poon, Low, \& Yong, 2004). He also considered that the satisfaction and progress of students in e-learning education are influenced by the facilities and technology infrastructure and support that offered by the educational institution.

A well-designed course is possible to be accepted easily by students (Gan, 1998; Parker, 1997). Furthermore, it improves students' access to providing course information (Carlson \& Zhao, 2004). According to Selim (2005), the self-learning programs of a series of online courses should include a variety of support services such as seminars, research about relevant courses in other websites, presentation by using multimedia either animation or narrative, instead of using references from books (Zhang, Zhao, Zhou,\& Nunamaker, 2004). Rosenberg and Foshay (2002) claimed that the management of knowledge enhances the creativity and information sharing between students and professors. Students are able to understand and learn the courses easily by sharing their knowledge with other students and with their professors and that could be a new educational model about e-learning education (Poon, Low, \& Yong, 2004).

The factor "support from the educational institution" includes 5 determining variables (A4.1-A4.5), which were used by Selim (2005) for investigating the effectiveness and efficiency of the technical support of educational institutions, library services and the reliability of laboratories.

\subsection{Use of Web Based Learning (Variable A5)}

Several researchers, from the field of development of technology and informatics, considered the use of technology as an independent variable (Davis, 1989). In fact, the researchers need to know why people are hesitant towards the use of new technology, such as e-learning, in order to evaluate practical methods and to predict how people will react. Those mentioned previously will aim to increase the acceptance of technology by users through the modification of technologies and implementation procedures (Venkatesh \& Davis, 2000).

In our case, apart from the various factors which either positively or negatively affect student's mind about the Web Based Learning, it is clear that their attitude is defined by their willingness and interest to experiment. Certainly, their professors, their knowledge and their experiences, the available technology and the support from the educational institution affect their attitude but these factors do not indicate the intention of students to use Web Based Learning.

In the factor "Use of Web Based Learning" there are 5 determining variables (A5.1-A5.5), which were used by Selim (2006), in order to test the students' intention according to the use of Web Based Learning. In other words, we want to test how willing they are for following that kind of e-learning.

\section{METHODOLOGY}

The main aim of this study is to present, investigate and assess the factors that influence and lead to successfully use of the Web Based Learning. It also studies the dependence of the proposed five factors and their interrelationships, and rank them according to their significance.

In order to fulfil the abovementioned study objectives, a model is proposed, for the acceptance of online education by students, as this is depicted in Figure 1. The adopted variables of the model are: (A1.) Instructors' characteristics, (A2.) Students' characteristics, (A3.) Information and Communications Technology, (A4.) The information technology used by the school (Support), (A5.) Intention of use of the Web Based Learning.

According to the proposed model, four variables were defined as critical factors: Instructors' characteristics (Instructor), Students' characteristics (Student), Information and Communications 


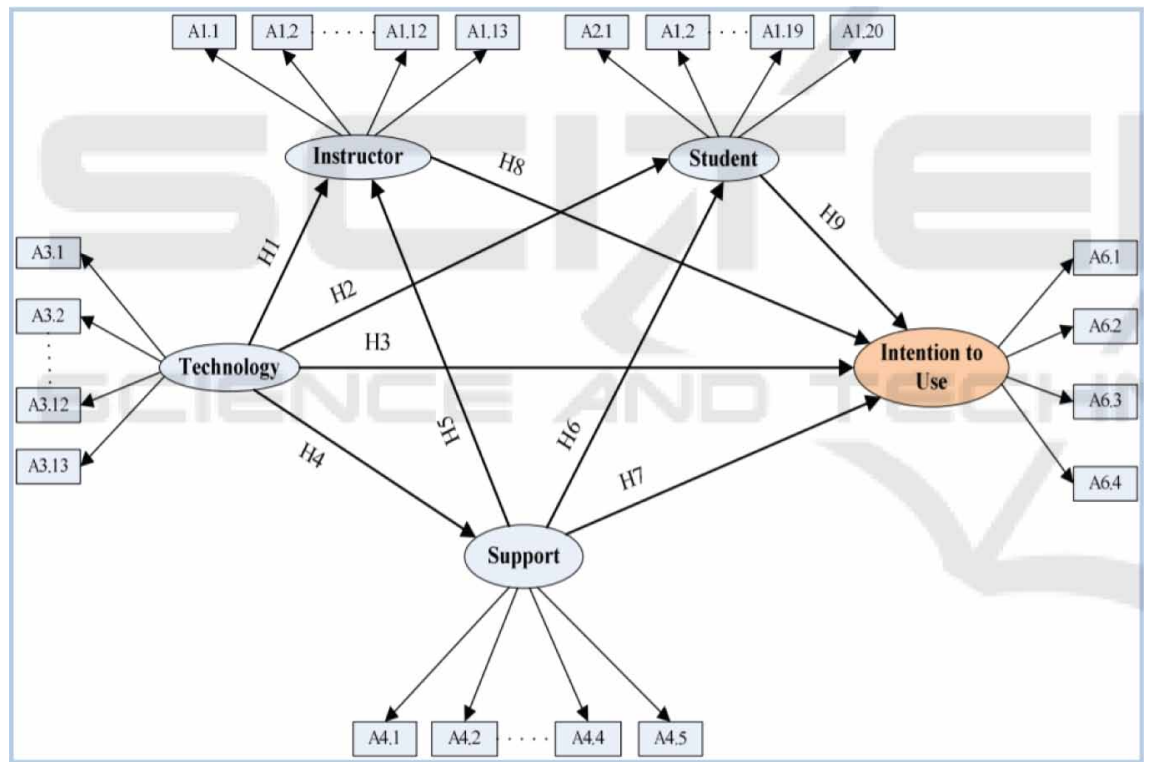

Technology (Technology) and the Support by the school (Support). In addition, to measure the intention of students to use the Web Based Learning, a fifth deterministic variable (Intention to Use) is used. A preliminary version of this methodology was presented by Valsamidis, Kazanidis, Aggelidis, Kontogiannis, \& Karakos (2016).

The conducted research follows the two dimensional framework for the design and natural science research in information technology of March and Smith (1995), for development and evaluation. In particular, a hypothetical model is planned and then assessed to investigate the factors that can influence the formation of students' intention to use the e-learning. In the tree categorization by Jarvinen (2001), this research belongs to the approaches for the development of innovative approaches and evaluation. Four hundred students of the Accounting department of TEI Eastern Macedonia and Thrace were answer a questionnaire. This research uses the structured approach. Also, the non-probabilistic sampling is used, which means that every student of TEI Eastern Macedonia and Thrace has the same probability to participate in the research. Beyond that, the method of systematic sampling is adopted. The number of four hundred (400) persons is a sufficient sample to provide representative results. The method of data collection has been done by a questionnaire that is consisting of 56 questions. From these questions 9 were referring to demographics, 13 to Instructor variable, 5 to Support, 20 to Student, 13 to Technology and 4 to Intention to use variable. All the questions except demographics were in 5 grade Likert scale from totally disagree to totally agree. The deterministic variables are the questions of our questionnaire.

After a thorough analysis, the questionnaire responses show us if the deterministic variables are suitable to measure the hidden variables and how they affect the formation of the students' intention in the adoption and use of a Web Based Learning. The analysis of our model is focused on the four hidden variables (factors), each determined by some deterministic variables.

The steps of the methodology are depicted in Figure 2.

After the measurements of the research, the reliability and validity test of the model is performed. Then, the computation of the factors for exploratory analysis through a multiple regression is performed, having as independent variables the computed factors of the model and as a dependent variable the intention to use according to the testing model. These results are recorded and evaluated 
Figure 2. The steps of the methodology

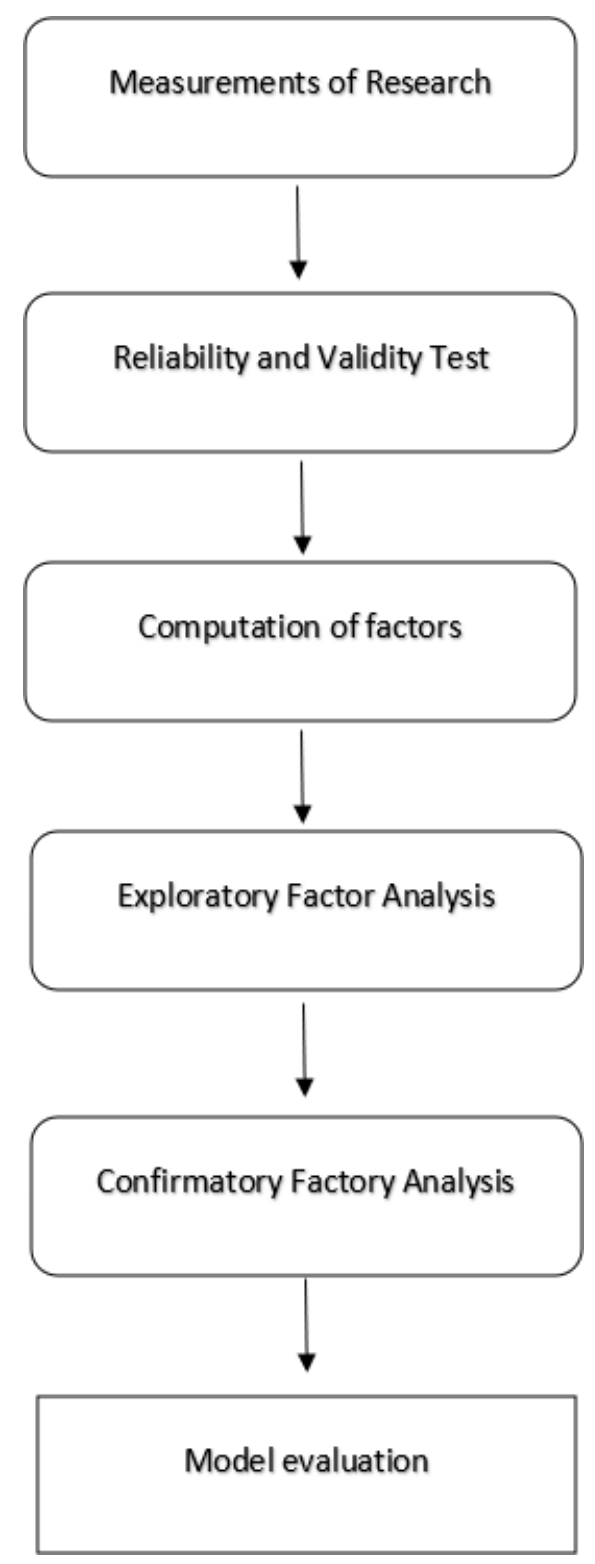

accordingly. Then, a confirmatory factor analysis is performed, where adaptability indices are assessed. According to Joreskog and Sorbom (1993), Hoyle (1995) and Byrne (2016), the ratio of minimum deviation with the degrees of freedom, the Comparative Fit Index (CFI), the Goodness of FIt statistic (GFI) and the Root Mean Square Error of Approximation (RMSEA) are the indices used by structural equation systems.

Based on the updated indices, some variables may be, removed so as to maximize the adjustment of the model. The decision to remove a variable or relationship or the addition of a relationship, based on revisions and corrections, reflects the substance. Thus, for the redefinition of the model, only the statistical significance of the relationship must be taken into account, as well as the recommendations 


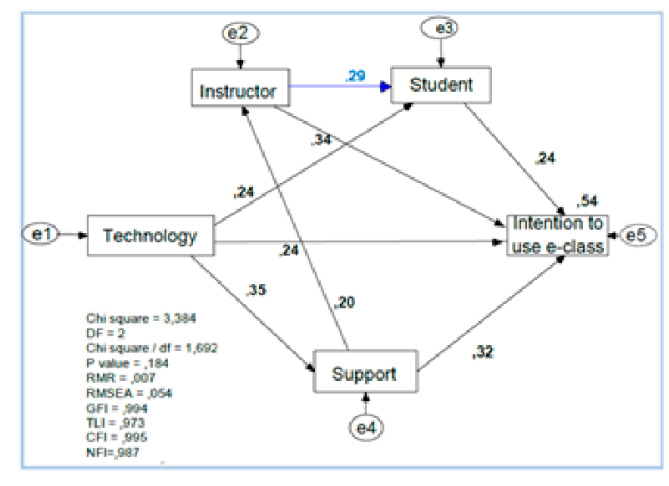

of modification coefficients that should have such values that the adaptability indices are within acceptable limits of the adopted methodology (Bollen, 1989; Green, Thompson, \& Poirier, 1999). In this way, variables or relationships are deleted, when it is no longer necessary to maintain the adjustment of the model.

For the exploratory factor analysis and descriptive statistics, correlations and reliability validation, the statistical package SPSS 19 were used. For the confirmatory factor analysis, the Structural Equation Modelling (SEM) with the AMOS software package was used.

\section{RESULTS}

After the application of the methodology the model has the structure and content which is depicted in Figure 3 for acceptance and use of Web Based Learning. It also includes the capacity of causal relationships between factors that compose it, and the explained rate fluctuates as well.

Taking into account the acceptable margins of the adaptability coefficients, a generally very good fit of the data with the concerned model is observed. In particular, the indices CFI, GFI and NFI get value greater than 0.9 , which is considered the threshold of reliability, validity and adaptability to the data. The value of the index $x^{2}$ for the degrees of freedom to be with less than 3 and the value of RMSEA index is less than 0.1 ; these values were adopted as the upper limit of a fitness model. So, according to the values of adaptability coefficients, the model is proved as a valid and reliable model for analysis of the results and draw conclusions.

Table 1 presents the determinant of direct, indirect and total normalized (in unit) effects among the factors that comprise the proposed model for the acceptance and use of the Web Based Learning by the students. The coefficients of the paths can be used to decompose the correlations between the factors, which form the model of direct and indirect effects, corresponding to the direct and indirect paths shown by the arrows of causality model. The indirect effect of a variable $i$ to variable $j$, according to the rules of linear systems, is calculated from the summary of the coefficients multiplications of all the indirect paths from $\mathrm{i}$ to $\mathrm{j}$.

The model was initiated, having set the relationships between the factors to be considered together and the intended use of students on the Web Based Learning. The relationship between Technology and Instructors' Characteristics and the relationship between the Support and Students' characteristics were rejected. On the other hand, a new relationship between Instructors' characteristics and Students' characteristics arose.

It is worth noting that the strongest relationship in our final model is that between technology and the support from the school. The weakest is observed between the support of the school and instructor's characteristics. This makes sense because a school as good technical support has, the 
Table 1. Direct, indirect and total normalized effects between the factors that make up the proposed model of acceptance and use of Web Based Learning ( $D=$ Direct, I=Indirect, $T$ = Total Effect)

\begin{tabular}{|l|l|l|l|l|l|}
\hline & \multicolumn{1}{|c|}{$\begin{array}{c}\text { Technology } \\
\text { characteristics }\end{array}$} & $\begin{array}{c}\text { Support } \\
\text { Characteristics }\end{array}$ & $\begin{array}{c}\text { Instructors' } \\
\text { characteristics }\end{array}$ & $\begin{array}{c}\text { Students' } \\
\text { characteristics }\end{array}$ \\
\hline \multirow{4}{*}{$\begin{array}{l}\text { Support } \\
\text { Characteristics }\end{array}$} & $\mathrm{D}$ & 0.346 & & & \\
\cline { 2 - 6 } & $\mathrm{I}$ & & & & \\
\cline { 2 - 6 } & $\mathrm{T}$ & 0.346 & & & \\
\hline \multirow{3}{*}{$\begin{array}{l}\text { Instructors' } \\
\text { characteristics }\end{array}$} & $\mathrm{D}$ & & 0.198 & & \\
\cline { 2 - 6 } & $\mathrm{I}$ & 0.068 & & & \\
\cline { 2 - 6 } & $\mathrm{T}$ & 0.068 & 0.198 & & \\
\hline \multirow{3}{*}{$\begin{array}{l}\text { Students' } \\
\text { characteristics }\end{array}$} & $\mathrm{D}$ & 0.239 & & & \\
\cline { 2 - 6 } & $\mathrm{I}$ & 0.020 & 0.057 & 0.289 & \\
\cline { 2 - 6 } & $\mathrm{T}$ & 0.259 & 0.057 & 0.289 & \\
\hline \multirow{5}{*}{ Intention of use } & $\mathrm{D}$ & 0.243 & 0.321 & 0.336 & 0.236 \\
\cline { 2 - 6 } & $\mathrm{I}$ & 0.195 & 0.080 & 0.068 & \\
\cline { 2 - 6 } & $\mathrm{T}$ & 0.438 & 0.401 & 0.404 & 0.236 \\
\hline
\end{tabular}

better it will be or at least seems to be the technology to students. And vice-versa, as finer technology has, the better it will be or at least seems to students, the technical support. On the other hand, the only relationship between instructor and support is when the instructor assumes such responsibility, i.e. to fix something or help a student to something relevant.

Table 1 can give us enough results worth interpret. Initially, we observe that the instructor's characteristics have the strongest direct relationship with the intention to use. This probably indicates that the attitude and the knowledge of the instructor play an important role in the student's intention of use the Web Based Learning. On the other hand, the student's characteristics are weakest directly related to the intention of use. His/her own characteristics i.e., no shape his/her intention as strongly as other external factors.

Interests are the results of the overall relationships, namely computing and indirect from direct. The strongest relationship, longer observed, is between technology and the intention to use. While the direct relationship between them was particularly weak, the indirect was particularly strong with the result as a whole to have the strongest correlation model. The strong indirect relationship is probably due to the fact that technology is related to all the factors which affects. We have not to forget that education through Internet is a methodology that uses advanced technology. It is worth noting that the difference of total relationship among factors and intention of use is small. In particular, the relationships of intention to use with technology, students' characteristics, instructors' characteristics and support are in the same range. It is striking that the student's characteristics have a significantly weaker relationship with the intention to use. The same occurred with the direct relationship. The most likely explanation in this case is that the student is more influenced by external factors than by its own characteristics.

The instructor's ability to make the student feel welcome and encourage him/her, is the most important component of the factor that measures the style of teaching and the availability of the teacher.

The previous knowledge of the student on Information Technology is the most important component of the factor associated with the motivation and skills of the student. 


\section{DISCUSSION}

The findings of this study can be considered as reasonable, since the technical background of the instructor is not affected by the Institute's technology and also the characteristics of students are not affected by the quality and quantity of technical support. On the other hand, the characteristics of students are affected and shaped by the characteristics of instructors. Every instructor should be the coach and the advisor of the student. Generally, the characteristics and the progress of each student are dependent, to some extent, on the interactions s/he had with his/her instructors.

The order of significance among the five factors, based on the average of the coefficients is: students' characteristics, the intention of use, the technology, the instructors' characteristics and the support from the school. This result does not agree with the corresponding conclusion of Lim, Hong, $\&$ Tan (2008), who had found as the most significant factor the technical support from the school. It agrees, with Poon, Low, \& Yong (2004), who had also found students' characteristics, as the most important factor.

The process of searching in Internet seems to be the most important component of the factor that measures the ease of access and navigation on Internet, the navigation speed, ease of use of course websites, the efficiency of the interface, the reliability of communication between the students and the reliability of communication between student and teacher, which is consistent with the research of Masrom, Zainon, \& Rahiman (2008).

Access to the central library and the general support, are the most important components of the factor technical support of the school. The investigation showed that topics such as education via Internet, online information, electronic libraries and the ease of access push the student to positively evaluate this.

Students showed positive towards education via the Internet, stating that they would participate in such a future course. Similar was the finding by Selim (2005). The interest to the course by this method is the most important component for the students' intention to use Web Based Learning.

We point out that the technical background of the instructor is not affected by the technology but also the characteristics of students are not affected by the quality and quantity of technical support. On the other hand, students' characteristics are influenced and formulated by the characteristics of the instructor. It should be noted that the above results agree with most previous studies (Selim, 2006; Volery \& Lord, 2000; Al-Fadhli, 2009; Abbad, Morris, \& de Nahlik, 2009).

\section{CONCLUSION}

The purpose of this study was to present, investigate and assess the factors that influence and lead to successfully use of Web Based Learning. For this reason four variables were defined as critical factors in the proposed model. In addition, a fifth deterministic variable, Intention to use an e-learning platform was proposed to measure the intention of students to use the Web Based Learning. The results from the questionnaire responses revealed how the proposed variables affect students' intention in the use of an e-learning online platform that is used by a higher education department.

The findings of this study may help education stakeholders to adopt adequate policies and apply specific strategies regarding educational technology and e-learning.

The presented causal model explains 54\% of education acceptance criteria through Web Based Learning. However, this study has several limitations worth noting. The most important are the sample size is limited, the questionnaire size, the objectivity of the respondents, the level of education through Web Based Learning in Greece, the associative nature of the research and the adaptability indices of confirmatory factor analysis. In addition, this research does not study the type of use by the students of the e-learning platform. Papadakis et al. (2017) discover that e-learning platform Moodle was used merely as an electronic document repository and not as an effective learning tool. 
Recommendations for further research are the repetition of the study with new larger sample, that it will be applied in other universities to confirm the findings of the study. Since this causal model covers only the $54 \%$ of all the possible factors, more factors have to be discovered. Also in accordance with similar studies such as Papadakis et al. (2017) follow-up interviews can be conducted to solicit students' perceptions on intention to use the e-learning platform and the underlying reasons. Finally a twofold evaluation with research to other entities apart of the students (i.e. proper questionnaires for teachers, executives of school, and companies of advanced technology) would be useful. 


\section{REFERENCES}

Abbad, M. M., Morris, D., \& de Nahlik, C. (2009). Looking under the Bonnet: Factors Affecting Student Adoption of E-Learning Systems in Jordan. International Review of Research in Open and Distance Learning, 10(2). Advance online publication. doi:10.19173/irrodl.v10i2.596

Al-Fadhli, S. (2009). Factors Influencing the Acceptance of Distance Learning: A Case Study of Arab Open University in Kuwait. Online Journal of Distance Learning Administration, 12(3), 221-229.

Alexander, S. (2001). E-learning developments and experiences. Education + Training, 43(4/5), $240-248$. doi:10.1108/00400910110399247

Alhabeeb, A., \& Rowley, J. (2018). E-learning critical success factors: Comparing perspectives from academic staff and students. Computers \& Education, 127, 1-12. doi:10.1016/j.compedu.2018.08.007

Basak, S. K., Wotto, M., \& Bélanger, P. (2016). A framework on the critical success factors of e-learning implementation in higher education: A review of the literature. Int. J. Educ. Pedagog. Sci, 10(7), 2409-2414.

Bollen, K. A. (1989). Structural Equations with Latent Variables. Wiley Series in Probability and Mathematical Statistics. Wiley. doi:10.1002/9781118619179

Bures, E. M., Amundsen, C. C., \& Abrahmi, P. C. (2002). Motivation to learn via computer conferencing: Exploring how task-specific motivation and $\mathrm{CC}$ expectations are related to student acceptance of learning via CC. Journal of Educational Computing Research, 27(3), 249-264. doi:10.2190/R4WG-88TJ-C3VF-YQJ0

Byrne, B. M. (2016). Structural equation modeling with AMOS: Basic concepts, applications, and programming. Routledge. doi:10.4324/9781315757421

Carlson, K. S., \& Zhao, G. X. A. (2004). Collaborative learning: Some issues and recommendations. In Proceedings of the Centre for the Development of Technological Leadership Conference (CDTL). National University Singapore.

Chao, R. J., \& Chen, Y. H. (2009). Evaluation of the criteria and effectiveness of distance e-learning with consistent fuzzy preference relations. Expert Systems with Applications, 36(7), 10657-10662.

Cheawjindakarn, B., Suwannatthachote, P., \& Theeraroungchaisri, A. (2013). Critical success factors for online distance learning in higher education: A review of the literature. Creative Education, 3(08), 61-66. doi:10.4236/ ce.2012.38B014

Collis, B. (1995). Anticipating the impact of multimedia in education: Lessons from the literature'. Computers in Adult Education and Training, 2(2), 136-149.

Daniel, D. R. (1961). Management Information Crisis. Harvard Business Review.

Davis, F. D. (1989). Perceived usefulness, perceived ease of use, and user acceptance of information technology. Management Information Systems Quarterly, 13(3), 319-340. doi:10.2307/249008

Drennan, J., Kennedy, J., \& Pisarki, A. (2005). Factors affecting student attitudes toward flexible online learning in management education. The Journal of Educational Research, 98(6), 331-338. doi:10.3200/JOER.98.6.331-338

Folorunso, O., Ogunseye, O. S., \& Sharma, S. K. (2006). An exploratory study of the critical factors affecting the acceptability of e-learning in Nigerian universities. Information Management \& Computer Security, 14(5), 496-505. doi:10.1108/09685220610717781

Fredericksen, E., Pickett, A., Shea, P., Pelz, W., \& Swan, K. (2000). Student satisfaction and perceived learning with on-line courses: Principles and examples from the SUNY learning network. Journal of Asynchronous Learning Networks, 4(2), 7-41.

Friesen, N. (2005). Interoperability and Learning Objectives: An Overview of eLearning Standardization. Interdisciplinary Journal of Knowledge and Learning Objects, 1, 22-31.

Frimpon, M. (2011). A Re-Structuring of the Enterprise Resource Planning Implementation Process. International Journal of Business and Social Science, 3, 1. 
Gan, S. L. (1998). Online distance education program: Problems and issues. Proceedings of the International Conference on Information Technology and Multimedia 1998, 25-29.

Govindasamy, T. (2002). Successful implementation of e-Learning; Pedagogical considerations. The Internet and Higher Education, 4(3-4), 287-299. doi:10.1016/S1096-7516(01)00071-9

Green, S. B., Thompson, M. S., \& Poirier, J. (1999). Exploratory Analyzes to Improve Model Fit: Errors Due to Misspecification and a Strategy to Reduce Their Occurrence. Structural Equation Modeling, 6(1), 113-126. doi:10.1080/10705519909540122

Haynes, R. M., Pouraghabagher, R., \& Seu, A. (1997). Interactive distance education alliance (IDEA): Collaborative model delivers on demand'. The Journal: Technological Horizons in Education, 24(8), 60-63.

Honey, P. (2001). E-learning: A performance appraisal and some suggestions for improvement. The Learning Organization, 8(5), 200-203. doi:10.1108/EUM0000000005913

Hoyle, R. H. (1995). Structural Equation Modelling: Concepts, Issues, and Applications. SAGE Publications. Järvinen, P. (2001). On research methods. Opinpajan kirja.

Joreskog, K. (1984). LISREL VI-Analysis of Linear Structural Relations by Maximum Likelihood Instrumental Variables, and Least Square Methods. User's Guide. Department of Statistics, University of Uppsala.

Kashiramka, S., Sagar, M., Dubey, A. K., Mehndiratta, A., \& Sushil, S. (2019). Critical success factors for next generation technical education institutions. Benchmarking. Advance online publication. doi:10.1108/BIJ-062018-0176

Latifah, A. L., \& Ramli, B. (2005). Priority-satisfaction survey: A tool in developing effective retention strategies. In Proceedings of the Conference on Research in Distance and Adult Learning in Asia. Open University of Hong Kong.

Lim, B., Hong, K. S., \& Tan, K. W. (2008). Acceptance of e-learning among distance learners: A Malaysian perspective, In Hello! Where are you in the landscape of educational technology? Proceedings of Ascilite Conference.

MacDonald, J. (2001). Exploiting online interactivity to enhance assignment development and feedback in distance education. Open Learning, 16(2), 179-189. doi:10.1080/02680510120050334

March, S. T., \& Smith, G. F. (1995). Design and Natural Science Research on Information Technology. Decision Support Systems, 15(4), 251-266. doi:10.1016/0167-9236(94)00041-2

Masrom, M., Zainon, O., \& Rahiman, R. (2008). Critical Success in E-learning: An Examination of Technological and Institutional Support Factors. International Journal of Cyber Society and Education, 1(2), 131-142.

McAlister, M. K., Rivera, J. C., \& Hallam, S. (2001). Twelve Important Questions to Answer Before You Offer a Web Based Curriculum. Online Journal of Distance Learning Administration, 4(2), 35-47.

McIntyre, D. R., \& Wolff, F. G. (1998). An experiment with WWW interactive learning in university education. Computers \& Education, 31(3), 255-264. doi:10.1016/S0360-1315(98)00025-6

McPherson, M. A., \& Nunest, J. M. (2008). Critical issues for e-learning delivery: What may seem obvious is not always put into practice. Journal of Computer Assisted Learning, 24(5), 433-445. doi:10.1111/j.13652729.2008.00281.x

Mitra, A., Lenzmeier, S., Steffensmeier, T., Avon, R., Qu, N., \& Hazen, M. (2000). Gender and computer use in an academic institution: Report from a longitudinal study. Journal of Educational Computing Research, 23(1), 67-84. doi:10.2190/BG2M-A5ER-KV7Y-N0J5

Ndubisi, N. O. (2004). Factors influencing e-learning adoption intention: Examining the determinant structure of the decomposed theory of planned behaviour constructs. Paper presented at the HERDSA 2004 Conference. Retrieved December 2, 2016, from http://www.herdsa.org.au/conference2004/Contributions/RPap ers/P057-jt.pdf

Ngai, E. W. T., Poon, J. K. L., \& Chan, Y. H. C. (2007). Empirical examination of the adoption of WebCT using TAM. Computers \& Education, 48(2), 250-267. doi:10.1016/j.compedu.2004.11.007 
Ong, C.-S., Lai, J.-Y., \& Wang, Y.-S. (2004). Factors affecting engineers' acceptance of asynchronous e-learning systems in high-tech companies. Information \& Management, 41(6), 795-804. doi:10.1016/j.im.2003.08.012

Papadakis, S., Kalogiannakis, M., Sifaki, E., \& Vidakis, N. (2017). Access moodle using smart mobile phones. A case study in a Greek University. In Interactivity, Game Creation, Design, Learning, and Innovation (pp. 376-385). Springer.

Papp, R. (2000). Critical success factors for distance learning. Paper presented at the Americas Conference on Information Systems, Long Beach, CA.

Parker, A. (1997). A distance education how to manual: Recommendations from the field. Educational Technology Review, 8, 7-10.

Poon, W. C., Low, L. T., \& Yong, G. F. (2004). A study of Web-based learning (WBL) environment in Malaysia. International Journal of Educational Management, 18(6), 374-385. doi:10.1108/09513540410554031

Rockart, J., \& Bullen, C. (1981). A primer on critical success factors. Center for Information Systems Research Working Paper No 69. Sloan School of Management, MIT.

Rosenberg, M. J., \& Foshay, R. (2002). E-learning: Strategies for delivering knowledge in the digital age. Performance Improvement, 41(5), 50-51. doi:10.1002/pfi.4140410512

Saadé, R., \& Bahli, B. (2005). The impact of cognitive absorption on perceived usefulness and perceived ease of use in on-line learning: An extension of the technology acceptance model. Information \& Management, 42(2), 317-327. doi:10.1016/j.im.2003.12.013

Sela, E., \& Sivan, Y. (2009). Enterprise E-Learning Success Factors: An Analysis of Practitioners' Perspective (with a Downturn Addendum). Interdisciplinary Journal of E-Learning and Learning Objects, 5(1), 335-343. doi: $10.28945 / 81$

Selim, H. M. (2005). Critical success factors for e-learning acceptance: Confirmatory factor models. Computers and Education. Retrieved February 6, 2016, from http://mail.phy.bg.ac.yu/ marijam/milos/science7.pdf

Selim, H. M. (2006). E-learning acceptance model (ELAM). Emerging Trends and Challenges in IT Management.

Selim, H. M. (2007). Critical success factors for e-learning acceptance: Confirmatory factor models. Computers \& Education, 49(2), 396-413. doi:10.1016/j.compedu.2005.09.004

Shuell, T. J., \& Farber, S. L. (2001). Students' perceptions of technology use in college courses. Journal of Educational Computing Research, 24(2), 119-138. doi:10.2190/YWPN-H3DP-15LQ-QNK8

Sigala, M. (2001). Factors Evaluation for the Development and Design of Distance Education via Internet. Proceedings of the 1st Hellenic Conference in Open and Distance Education.

Soong, B. M. H., Chan, H. C., Chua, B. C., \& Loh, K. F. (2001). Critical success factors for on-line course resources. Computers \& Education, 36(2), 101-120. doi:10.1016/S0360-1315(00)00044-0

Tolhurst, D., \& Debus, R. L. (2002). Influence of prior knowledge, attitudes, ability, and activity structure on students' learning and use of software. Journal of Educational Computing Research, 27(3), 275-313. doi:10.2190/12B7-RAG9-9QUR-61K6

Valsamidis, S., Kazanidis, I., Aggelidis, V., Kontogiannis, S., \& Karakos, A. (2016). Critical Success Factors for the Acceptance and Use of an LMS-The Case of e-CLASS. Proceedings of CSEDU 2016, 331-338.

Venkatesh, V., \& Davis, F. (2000). A theoretical extension of the technology acceptance model: Four longitudinal field studies. Management Science, 46(2), 186-204. doi:10.1287/mnsc.46.2.186.11926

Volery, T., \& Lord, D. (2000). Critical Success Factors in Online Education. International Journal of Educational Management, 14(5), 216-223. doi:10.1108/09513540010344731

White, S. (2007). Critical success factors for e-learning and institutional change-Some organisational perspectives on campus-wide e-learning. British Journal of Educational Technology, 38(5), 840-850. doi:10.1111/j.14678535.2007.00760.x

Zhang, D., Zhao, L., Zhou, L., \& Nunamaker, J. Jr. (2004). Can e-learning replace classroom learning? Communications of the ACM, 47(5), 75-79. doi:10.1145/986213.986216 
loannis Kazanidis is an adjunct assistant professor at Eastern Macedonia and Thrace Institute of Technology, Greece. He has published more than 100 papers in international journals and conferences. His research interests mainly focus on Information Systems and particularly on adoption of innovations in different fields of study on interaction design, educational technology, knowledge management, augmented reality, and user experience design.

Stavros Valsamidis received a five-year Electrical Eng. Diploma from Department of Electrical Eng., University of Thessaloniki, Greece, an MSc in Computer Science from University of London, UK and his PhD from the Department of Electrical and Computer Eng., University of Thrace, Greece. He is an Associate Professor in the Dept. of Accounting and Finance, Eastern Macedonia and Thrace Institute of Technology, Greece. He has published more than 110 papers in international journals and conferences. His research interests are in the areas of database systems, data mining and web applications assessment.

Sotirios Kontogiannis graduated from Democritus University of Thrace, Department of Electrical and Computer Engineering. He received an MSc in Software Engineering and PhD in the research area of algorithms and network protocols for distributed systems, from the same department. He worked as a software developer for more than ten years in the private sector .and participated into SME research and development projects. We also worked as a contract assistant professor at the Dept. of Business administration, TEI of Western Macedonia, for six years and as a contract lecturer at the Dept. of Informatics \& Telecommunications Eng., University of Western Macedonia. His research interests focus on the areas of distributed systems, artificial intelligence, Al algorithms, sensor networks, middleware protocols and computer networks. He is currently a scientific staff member and director of the Distributed micro-computers laboratory (http://kalipso.math.uoi.gr/microlab), at the Applied Mathematics and Engineering research section of the Department of Mathematics, University of Ioannina.

Soultana Ellinidou was born in Ptolemaida, Greece. She graduated from Department of Informatics and Telecommunications Engineering of University of Western Macedonia in 2016. She joined the OPERA Wireless Communications Group in January 2017 as a PhD student and her work is mainly oriented towards communication protocols and system architecture for secure cloud-of-chips. 